\title{
Designated trainers
}

The practice of medicine is one of the most attractive ways of earning a living. Hours are long, and for juniors financial rewards are modest and career prospects uncertain. Yet every year medicine attracts many of the brightest sixth formers. The mix of service to patients, teaching students and younger doctors, and research that with different weightings make up the working life of consultants gives continuing interest and variety to all the hospital specialties. Added to this traditional trinity is an increasing need for managerial skills. The exercise of all these skills and the endless diversity of patients make the practice of medicine a rewarding way of spending a working life. No wonder there are many general practitioners in their 70 s still doing a full day's work.

Most hospital doctors are employed by health authorities and their contracts are based on their service commitment. The Secretary for Social Services has a statutory responsibility to provide for research and teaching within the National Health Service (NHS) but at times when finance is tight both these components of medical practice suffer. Within the NHS financial rewards have always been linked to service, while status within the profession is often seen to be more closely related to undergraduate teaching and research. Regrettably status cannot compete with financial rewards particularly in specialities where private practice causes major distortions in the pattern of provision of care. Health authorities know that the quality of medical care cannot be maintained where teaching and research are squeezed out but in a climate where there is increasing emphasis on efficiency, and statistical indices are being adopted to identify good performance there is a strong temptation to allow less time in the working day for these vital functions and to assume that consultants' working hours can be stretched to encompass research and teaching by working at nights and weekends.

Education for general practice is a late arrival on the postgraduate scene and has been able to avoid the trap of hospital medicine. Because general practitioners are paid as independent practitioners and their earnings relate to workload, vocational training had to be developed using a system that recognized that trainers would need to be reimbursed for the time they gave up to teaching. As a result there has never been the automatic assumption that everyone in the career grade would be expected to teach. Criteria for appointment of trainers were spelt out rationally. Those general practitioners who satisfy the criteria and recruit trainees are expected to devote the equivalent of two sessions a week to training. Trainees are supernumerary to establishment and have a one-toone relationship with their trainers. Every trainee reports on his trainer and no trainer is allowed to go on without regular reassessment at five year intervals or less. Quite apart from the stimulus of participating in training, because only a tenth of principals become trainers the posts are seen to carry high status. Criteria for selection can be raised in the confidence that would-be trainers will clamber over the increasing number of obstacles to be appointed by their peers.

The General Medical Council's Education Committee has digested the experience of general practice and is now suggesting that 'designated trainers' have a role in hospital practice, for both pre-registration house officers and senior house officers or registrars in 'basic specialist education'. If their draft proposals are accepted, 'designated trainers' will need to be picked from the wider consultant body on the basis of rationally agreed criteria, and undergo reselection at specified intervals. Because of the scale of such an exercise there will need to be involvement of the regional postgraduate committees and regional College and Faculty advisers. The older Colleges have now appointed district based College Tutors and the duties and relationships of tutors and 'designated trainers' will need to be sorted out. 'Designated trainers' will need to be given time to supervise their juniors on a regular basis - assessing educational needs, gaps in knowledge or skills and advising on progress and career plans. Much thought needs to be given to the service implications of these proposals. Would some consultants who had been designated as trainers supervise the progress of trainee staff working for consultants who were not; or would junior staff in the training grades all work for consultants who had become 'designated trainers', while consultants who were not trainers would either have no junior staff or be supported by doctors in non-training career grades? In that case if a 'designated trainer' is not reselected what happens to the juniors he or she was training?

Will trainers be allowed contractual time to train? Is this one way of finding space to create more consultant posts? How will 'designated trainers' be selected and reselected? Will there be an appeals mechanism?

General practice has used the device of trainer reselection to embark on the wholesale raising of standards in general practice. National and regional criteria spell out the qualities required of trainers not 
only as educators but as practitioners. Criteria are revised upwards at regular intervals so that trainers are encouraged to raise their own standards or lose the enhanced status of trainer. Trainees participate in defining trainer criteria and in trainer selection and reselection.

Trainer selection has become a tool to make good general practice better. It could be used in hospital medicine in exactly the same way. The present consultant/junior doctor ratio of 1 to 1.8 would imply that every consultant can be a trainer. As 'Achieving a
Balance' is implemented that ratio will fall. Eventuall on numbers alone not every consultant can be trainer. Only some can be picked and the best method of choice would be some form of peer review. Once the myth that everyone who can do can teach is cast asid啇 we can start to recognize that teaching young doctoro is not only a privilege but also a duty that requires thought, time and teaching skill. Thought and time also needed to decide how 'designated trainers' should be chosen and on what criteria.

Elizabeth Shorẹ্

Regional Postgraduate Deant North West Thames Region British Postgraduate Medical Federation 33 Millman Street London WCIN 3EJ, UK 